\title{
The Effect of Drying Time on Mechanical Properties of Natural Rubber Latex (NRL) Film Filled with Nanocrystal Cellulose (NCC) from Corn Cobs Waste Using Dispersion Agent Polyvinylpyrrolidone (PVP)
}

\author{
Hamidah Harahap, Yuni Aldriani Lubis, Taslim, Iriany, Halimatuddahliana Nasution and Sutarman
}

\begin{abstract}
Vulcanisation shows how much the maturity process and can also be determined by the optimal time required for product. The longer of drying times can produce NRL films with the highest quality that can be commercialised to public. The purpose of this research was to determine the best time of drying time in producing NRL films filled with NCC from corn cobs using nano-sized filler prepared by strong acid hydrolysis, which had been dispersed in NRL compound. PVP is then employed as binder characterised by water binding properties and high biocompatibility. The production of NRL film begins with pre-vulcanization process that heated at 70 ${ }^{\circ} \mathrm{C}$, and followed by vulcanization process at $110{ }^{\circ} \mathrm{C}$ for 10 and 20 minutes. The mechanical and morphological properties of NRL films had been analysed. The results showed that longer time with the addition of PVP had better NRL film.
\end{abstract}

Keywords - natural rubber latex, nanocrystal cellulose, drying time, mechanical properties, morphological properties.

\section{INTRODUCTION}

Recently, NRL has become an inside solution. NRL is a natural product developed due to the challenge of promoting sustainable development and ecological levels that are increasingly raising public awareness [1]. NRL is an important commodity in Indonesia produced from the main staple of Hevea brasiliensis and formed into rubber particle suspension (cis-1,4 polyis oprene) and non rubber in water [2].

NRL products generally have lower mechanical properties with natural rubber latex products that have been given fillers [3].

Hamidah Harahap, Yuni Aldriani Lubis, Taslim, Iriany, Halimatuddahliana Nasution, Department of Chemical Engineering, Faculty of Engineering University of Sumatera Utara, Indonesia

Sutarman, Department of Mathematics, Faculty of Mathematics and Natural Science, University of Sumatera Utara, Indonesia
The additions of the contents in the NRL compound can strengthen the vulcanized NRL product, so its properties such as tensile strength are increased [4].

Several studies of modifications have been made in the form of cassava peel waste powder [5], kaolin [6], and nanocrystal cellulose from baggase which have good mechanical properties [2]. The modified filler can improve the mechanical properties of NRL products. The PVP used is a polymer binder so that it can bind to each NRL matrix other with filler.

Therefore, this study impacts the drying on the mechanical properties of NRL products with NCC and PVP dispersion agent.

\section{PROCEDURE}

\section{A. Materials}

Raw materials (corn cob waste) are obtained from local market, Jalan Gaperta Ujung, Kampung Lalang, Medan, North Sumatera, Indonesia. High Ammonia Latex 60\% obtained from local market in Medan, Indonesia. Sulfur, Zinc Oxide $(\mathrm{ZnO})$, Zinc Diethyldithiocarbamate (ZDEC), and Antioxidants (AO) as a curative for the pre-vulcanization process of natural rubber latex obtained from Farten Technique (M) Sdn Bhd, Pulau Penang, Malaysia.

The nanocrystal cellulose filler is obtained from acid hydrolys is process ie corncob waste with $45 \%$ sulfuric acid. PVP (PVP) as a binder.

\section{B. Preparation of NRL}

\section{B.1 Pre-vulcanisation}

$10 \%$ NCC filler is made with a dispersion process consisting of NCC, water, and PVP inside the Ball Mill. The PVP used is $1 \%$ (weight percent). Then the ingredients were mixed with NRL for the pre-vulcanization process as shown in Table I. Table I below shows the formulation of NRL compound for the pre-vulcanization process.

Concentrated latex is added with $10 \%$ filler dispersion system. The pre-vulcanization process is carried out at $70{ }^{\circ} \mathrm{C}$ 
until cured condition based on chloroform at number 3 .

TABLE I

UNIT S FOR PRE-VULCANISATION PROCESS

\begin{tabular}{|l|c|}
\hline \multicolumn{1}{|c|}{ Compounds } & $\begin{array}{c}\text { Weight } \\
\text { (gram) }\end{array}$ \\
\hline $60 \%$ High Ammonia Latex & 166,7 \\
\hline $50 \%$ Sulfur Dispersion & 3 \\
\hline $50 \%$ ZDEC Dispersion & 3 \\
\hline $30 \%$ ZnO Dispersion & 0,83 \\
\hline $50 \%$ Antioxidant & 2 \\
\hline $10 \%$ KOH & 3 \\
\hline $10 \%$ NCC Fillers & $2,4,6,8$ \\
\hline
\end{tabular}

\section{B.2 Vulcanisation}

After the pre-vulcanization process, NRL compound is formed into a film by dipping $10 \% \mathrm{Ca}\left(\mathrm{NO}_{3}\right)_{2} \%$ coagulant using a thinly cleaned steel plate. The process of vulcanization was carried out at $110{ }^{\circ} \mathrm{C}$ and a drying time variation of 10 minutes and 20 minutes.

\section{Mechanical Testing and Morphological Study}

The films were tested in accordance with ASTM D412 using INSTRON 5565. With a cross-head speed of 500 $\mathrm{mm} / \mathrm{min}$. Tensile strength, elongation at breaks, $\mathbf{M}_{100}$ and $\mathbf{M}_{300}$ have been analyzed. Then, morphological studies were analyzed using JEOLJSM 6360-LA Scanning Electron Microscope (SEM). The film is characterized by Fourier Transform Infra-Red (FTIR) through Shimadzu IR-Prestige 21.

\section{Determination of Crosslink Density}

The NRL product is made into small pieces of about 0.2 grams. Data to the calculation of cross density is obtained from the swelling of the data performed in accordance with ASTM D471. Then, the calculation of crosslink density is performed using the equations given by Flory-Rehner according to the following equation [7]:

$$
\left(2 M_{C}^{-1}\right)=\frac{\left[-\ln \left(1-V_{r}\right)-V_{r}-\chi \cdot V_{r}^{2}\right]}{2 \cdot \rho_{N R L} \cdot V_{0}\left(V_{r}^{1 / 3}\right)}
$$

$\left(2 \mathrm{M}_{\mathrm{C}}{ }^{-1}\right)$ is the physical crosslink density, $\mathrm{V}_{0}$ and $\chi$ is the molar volume and the solvent interaction parameter (for toluene, $\mathrm{V}_{0}=108.5 \mathrm{~mol} . \mathrm{cm}^{-3}$ and $\left.\chi=0.39\right), \rho_{\mathrm{NRL}}$ is the density for the rubber network $=0.932[8] . \mathrm{V}_{\mathrm{r}}$ is the volume fraction of the rubber in the stolen gel which can be obtained by using the following equation:

$$
\mathrm{V}_{\mathrm{r}}=\frac{\mathrm{W}_{\mathrm{d}} / \rho_{\mathrm{d}}}{\mathrm{W}_{\mathrm{d}} / \rho_{\mathrm{d}}+\mathrm{W}_{\mathrm{sol}} / \rho_{\mathrm{sol}}}
$$

Where $\mathrm{W}_{\mathrm{d}}$ and $\rho$ are the weight of dry rubber (for vulcanized rubber, $\rho_{\mathrm{d}}=0.9203 \mathrm{G} \cdot \mathrm{cm}^{-3}$ ) [9], and $\mathrm{W}_{\text {sol }}$ and $\rho_{\text {sol }}$ are the weight and density of the solvent (for toluene, $\rho_{\text {sol }}=0.87$ g. $\left.\mathrm{cm}^{-3}\right)$.

\section{RESULT S AND DISCUSSION}

\section{A. Crosslink density}

Fig. 1 shows the effect of drying time on crosslink density NRL film with PVP dispersion agent. When it was observed that NRL films with values higher than crosslink density occurred at the drying time for 20 minutes. Longer vulcanization times will increase curative materials and NCC fillers interact on latex particles and this forms more crosslinked bonding formations. Natural rubber latex film with 8 gram loading ( $1 \%$ by weight PVP) shows maximum value on crosslink density. The addition of longer filler loading for a long time is likely to inhibit the interaction between the curative and the filler and with the NRL matrix.

This is confirmed by Leroy (2013), that longer retrieval time will result in more crosslinks. However, the longer of drying time can also produce unstable crosslinks or known as reversion processes [10]. Reversion will cause the value of the mechanical properties to decrease. Usually, reversion occurs in conditions of vulcanization that are too long and use high temperatures [11]. From Fig. 1 above, it can be seen that the optimum cross link density occurs at 8 gram loading.

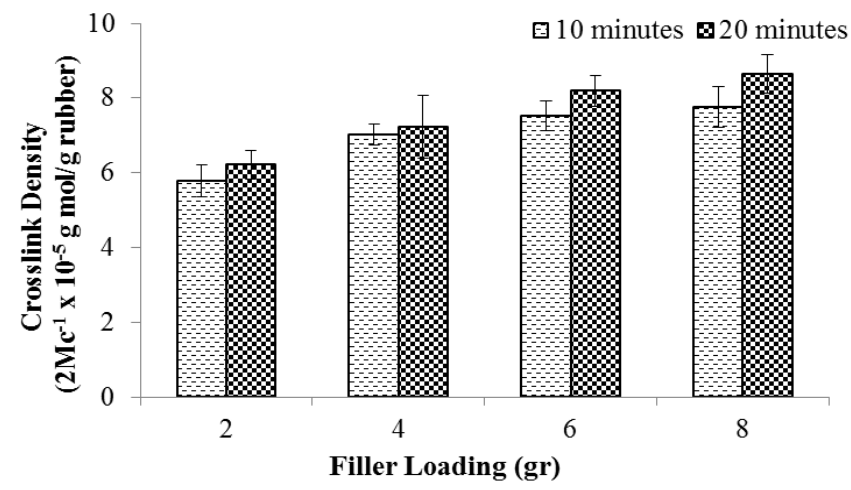

Fig. 1 Effect of Drying Time on Crosslink Density Natural Rubber Latex Film

\section{B. Tensile Strength}

Crosslink density value in Fig. 1 is an important value in determining the mechanical properties of a NRL film. From Fig. 2 below, the value of tensile strength is more likely to correspond to Fig. 1 where higher tensile strength values are found during longer of drying times. The filler loading of 6 grams (1\% by weight PVP) gives the highest value to the tensile strength of NRL film. This indicates that the PVP as a binder has reached its maximum capacity in binding the surface area of the NRL matrix so as to create a strong interaction between the NRL and the NCC filler. This is made clear by Leroy (2013), that the higher the crosslink density the higher the tensile strength. However, when crosslink density passes a certain point the tensile strength will decrease [10]. 
Then when the NRL product is stretched, the crosslinking bond in the NRL product has a fast response capability to withstand the stress distribution of the latex film itself. Therefore, it takes more power to decide. However, at the loading of 8 grams (1\% by weight of PVP), tensile strength decreased significantly. This occurrence may be due to filler agglomeration in NRL films thus exacerbating the condition of NRL film.

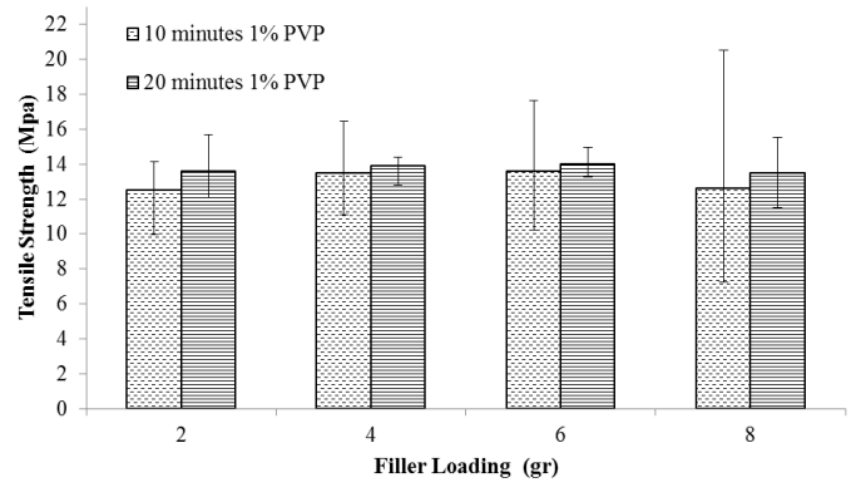

Fig. 2 Effect of Drying Time on Tensile Strength of Natural Rubber Latex Film

\section{Elongation at Break}

Fig. 3 indicates that the dried NRL product within 20 minutes gives a higher yield on elongation at break than the dried product in 10 minutes. The addition of filler will give stiffness to NRL film product. Thus, elongation at break will decrease. It was shown that the lowest elongation at break without the addition of PVP for second of drying time. However, the addition of a further PVP of up to $1 \%$ by weight makes the NRL product more elastic than an unmodified NRL film. This can be attributed to the function of PVP as a dispersion agent which can bind the relationship between the filler with NRL film.

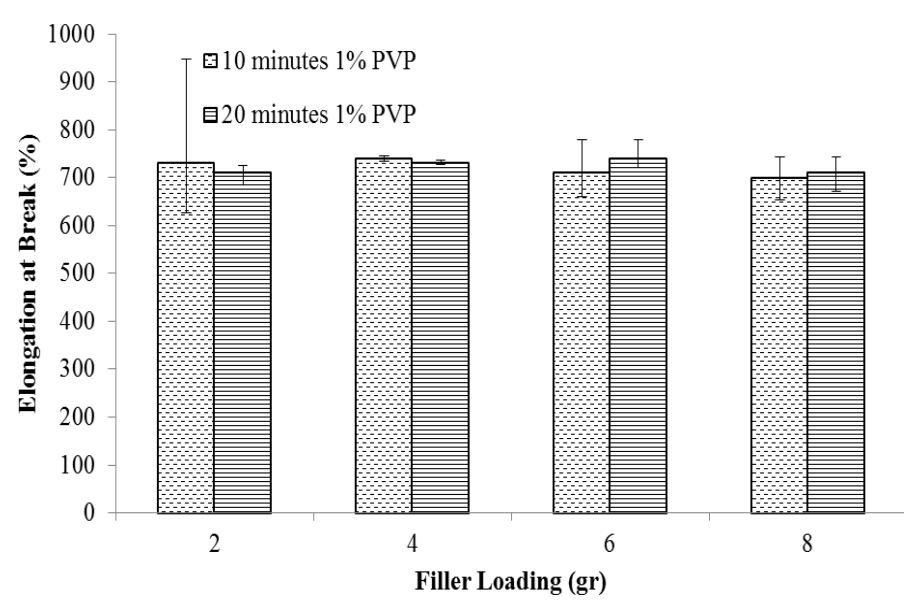

Fig. 3 Effect Drying Time on Elongation at Break of Natural Rubber Latex Film
D. $M_{100}$ and $M_{300}$

Fig. 4 shows the effect of drying time on $M_{100}$ and $M_{300}$ NRL products containing nanocrystal cellulose for 10 minutes and 20 minutes of drying time.

In $\mathrm{M}_{100}$, this shows a relatively similar result for loading of 2 , 4, 8 grams for 10 minutes. While at 20 minutes, the results are relatively fluctuating. At the $\mathrm{M}_{300}$ both at 10 minutes and 20 minutes are also relatively fluctuating. This is due to the increase of NCC filler in NRL product with an exaggerated PVP dispersion agent so that the filler is not evenly distributed on the NLR film matrix.

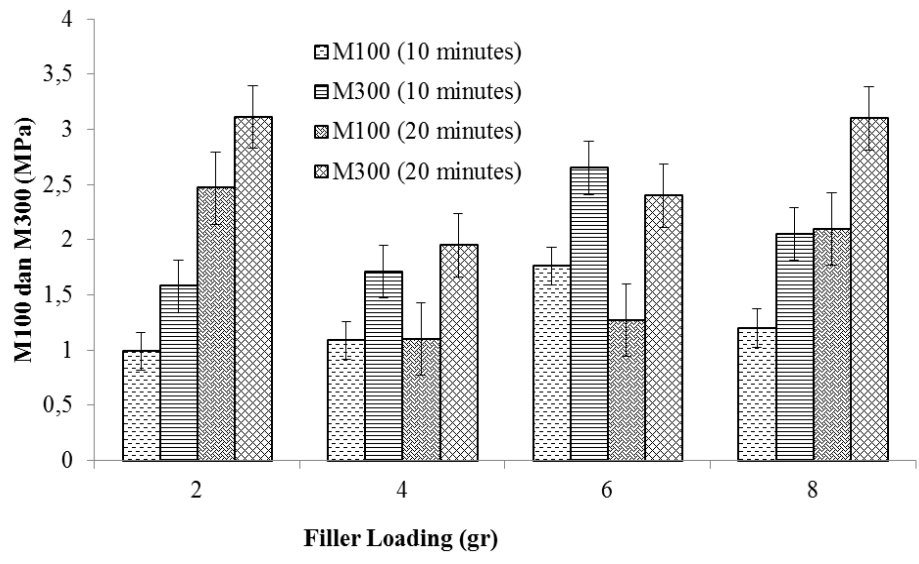

Fig. 4 Effect of Drying Time on Natural Rubber Latex Films and Polyvinylpirolidone Dispersion Agents on $\mathrm{M}_{100}$ and $\mathrm{M}_{300}$

\section{E. Characterization of Fourier Transform Infra-Red (FTIR)}

Fig. 5 shows the FTIR characteristics of NRL products without and with NCC fillers and PVP dispersion agents.

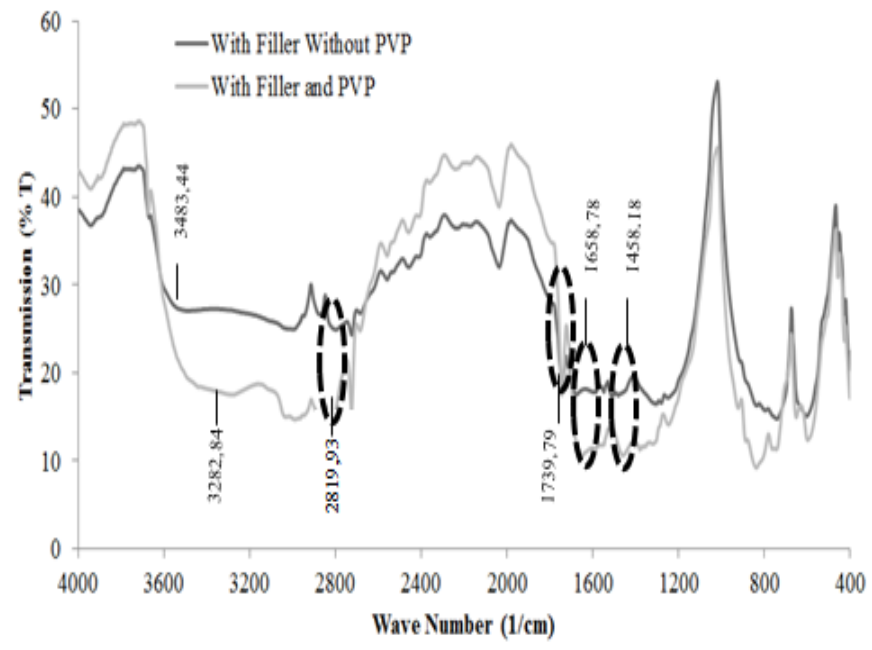

Fig. 5 Results of FTIR NRL with filler without PVP and NRL with Filler and PVP

NRL products with non PVP and NRL fillers with PVP-filled fillers show different steepness. This indicates that PVP has an important role in dispersing and binding natural rubber latex products.

The sharper peak absorption at wave number $1658,78 \mathrm{~cm}^{-1}$ in FTIR characteristics of NRL product is existnce of the addition of PVP. The absorption peak at $1658.78 \mathrm{~cm}^{-1}$ wave number indicates the presence of the $\mathrm{C}=\mathrm{C}$ group in which this group 
represents the existence of the vinyl group. This vinyl group is carried by PVP where the addition of PVP can stabilize the surface of the NRL product (interface) and increase the curing rate and have compatibility with the NCC filler caused by its vinyl content. This is confirmed by Koczkur (2015), in which the PVP serves as a surface stabilizer, increases maturity, dispersant nanoparticles, and reducing agents as shown, their role depends on synthetic conditions [12].

In previous absorption peaks on wave numbers have been formed but not very prominent, this is because cellulose compounds have $\mathrm{C}=\mathrm{C}$ groups as well. The result spectra of FTIR of NCC gives the peaks of the absorption spectra with the number of waves that appear at 3282.84, 3483.44, 1658.78, 2819,93 , and $1739,79 \mathrm{~cm}^{-1}$. Large trends at wave numbers 3282.84 and $3483.44 \mathrm{~cm}^{-1}$ indicate the presence of

-OH groups (3000-3750 $\mathrm{cm}^{-1}$ refer to $-\mathrm{OH}$ stretching). At the absorption peak with the wave number $1658.78 \mathrm{~cm}^{-1}$ indicating the presence of the $\mathrm{C}=\mathrm{C}$ group and at the absorption peak with the wave number $2819.93 \mathrm{~cm}^{-1}$ indicates the presence of $\mathrm{CH}$ group which proves the presence of a $\mathrm{CH}$ bond at the end of the cellulose structure and $\mathrm{CO}$ of carbonyl on the number wave $1739,79 \mathrm{~cm}^{-1}$ which is also typical cellulose group. This indicates that the NCC filler has been mixed with the NRL matrix.

In addition, Fig. 5 also shows a decrease in the intensity of absorption peaks at $1458.18 \mathrm{~cm}^{-1}$ wave numbers indicating the presence of $\mathrm{CH}_{3}$ (alkane groups) derived from the NRL isoprene structure. The peak absorption intensity peak decrease occurs due to the addition of the filler provided either the added dispersion agent of PVP or not.

\section{F. Scanning Electron Microscope (SEM)}

The NRL product fracture is then analyzed by SEM shown by Fig. 6 .

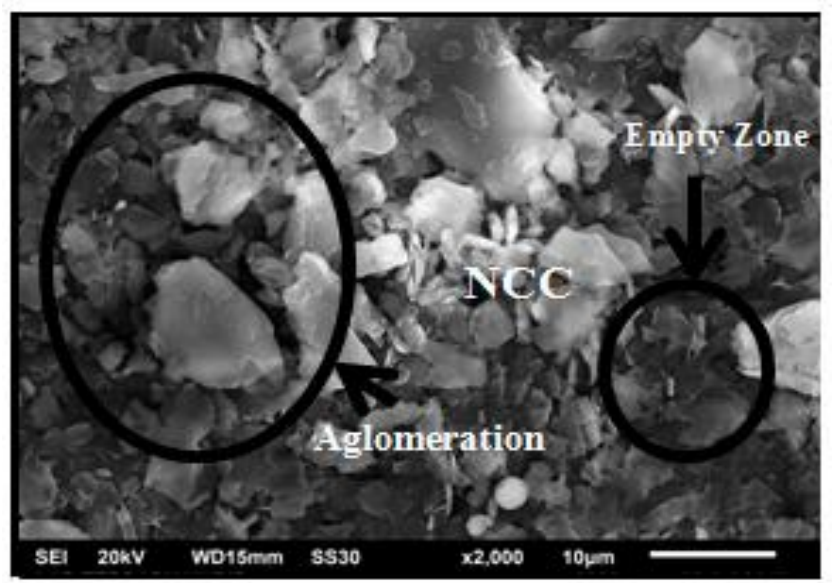

(a)

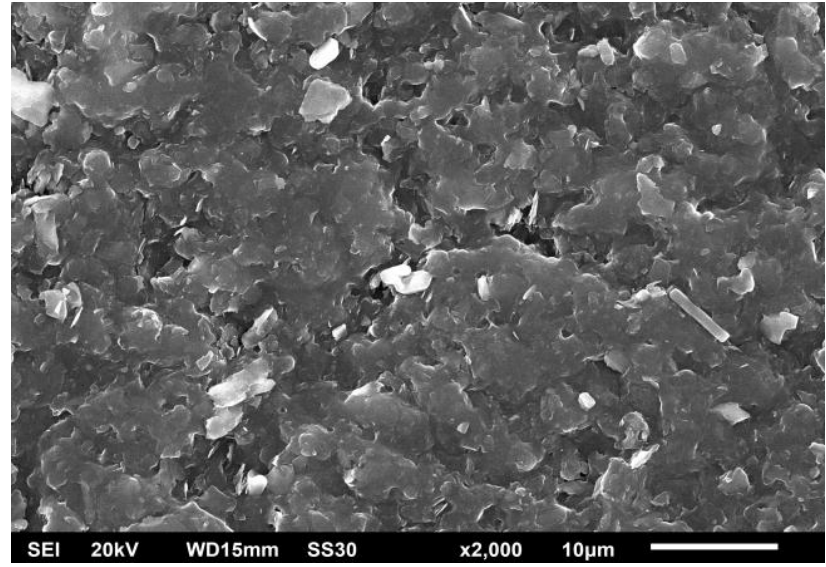

(b)

Fig. 6 SEM analysis of NRL film

1. With the Fill Without Polyvinylpirolidone Filling Using Magnification $2000 \mathrm{X}$

2. By Loading Filled and Polyvinylpirolidone Using

Magnification $2000 \mathrm{X}$

Fig. 6 (a) indicates the occurrence of agglomeration and the presence of NCC particles. This is caused by nondispersed filler of NCC. In addition, there is an empty zone where particle of NCC from corn cob particles are not completely dispersed in NRL.

Fig. 6 (b) shows a smooth surface where particles of the NRL film and the curative materials are well arranged and more evenly distributed on the surface of the film. This is approprite with the fact that PVP has worked as a dispersion agent and this is seen in the mechanical properties of NRL film.

\section{CONCLUSION}

It is observed that utilization of PVP as dispersion agent can modify NCC properties. It also shows that PVP provides better mechanical properties on NRL products such as tensile strength until the addition of $1 \%$ wt of PVP. The highest crosslink density was obtained at the addition of $1 \%$ wt of PVP for 20 minutes. Thus, the longer of drying time will improve the properties of NRL products such as crosslink density, tensile strength, tensile modulus, and elongation at break. The addition of PVP also improve the interfacial strength between matrix and filler as shown in FTIR analysis and SEM micrographs.

\section{REFERENCES}

[1] Thuraisingam, Jayshree., Arun Gupta, and Malini Subramaniam., "Natural Rubber Latex (NRL) and rice starch as an alternative binder in wood composite industry", Australian Journal of Basic and Applied Sciences, Vol. 10, No. 17, 2016, pp 101-106.

[2] Harahap, Hamidah., Marfuah Lubis, Nuim Hayat and Sukardi., "Effect of Aging Process on Elongation at Break and Morphology of Natural Rubber Latex Film Filled With Nanocrystalline Cellulose and Alkanolamide", International Journal of ChemTech Research, Vol.9, No.11, 2016, pp 201-205.

[3] Baharin, A., Pun, M. Y., Ahmad, M. M. Y., and Nasir, Z. A. "Addition of Over Cured Latex to Compounded Uncompounded and Prevulcanised HA Latex". Natural Rubber Curing 
Development In Product Manufacture and Applications : A report of proceeding of the International Rubber Technology Conference, RRIMB. 1993.

[4] Hall, W. J., Zakaria, N., and Williams, P. T. "Pyrolysis of latex gloves in the presence of Y-zeolite". Waste management, Vol. 29, No. 2. 2009. pp 797-803.

[5] Harahap, H., K. Hadinatan, A. Hartanto., I. Surya, M. Ginting. "The Effect of Drying Temperature on Mechanical Properties of Natural Rubber Latex Products with Cassava Peel Waste Powder Modified Alkanolamide." Journal of Engineering Science and Technology. 2015. Pp 53 - 63.

[6] Harahap, Hamidah., Indra Surya., Hanafi Ismail., Erick Kamil., Emelya Khoesoema., Elmer Surya,. "The Effect of Drying Temperature on Mechanical Properties of the Natural Rubber Latex Products Filled with Kaolin Modified Alkanolamide'. Material Sciences and Technology. 2013.

[7] Ismail, H.; and Ruhaizat, T.A. "Effect of palm oil fatty acid on curing characteristics and mechanical properties of $\mathrm{CaCO} 3$ filled natural rubber compounds." Iranian Polymer Journal, 6(2), 1997. 97-104.

[8] Cai, H.H.; Li, S.D.; Tian, G.R.; Wang, H.B.; and Wang, J.H. "Reinforcement of Natural Rubber Latex Film by Ultrafine Calcium carbonate". Journal of Applied Polymer Science, 87(6), 2003, pp 982-985.

[9] E. H. Miller, "A note on reflector arrays (Periodical styleAccepted for publication)," IEEE Trans. Antennas Propagat., to be published.

[10] Leroy, Eric. Anouar Souid. Remi Deterre."A Continuous Kinetic Model of Rubber Vulcanization Predicting Induction and Reversion". Polymer Testing vol. 32. page. 575-582. 2013.

[11] Milani, G., E. Leroy. F. Milani.R. Deterre. Mechanistic Modeling of Reversion Phenomenon in Sulphur Cured Natural Rubber Vulcanization Kinetics. Polymer Testing (32). 2013 page. 10521063.

[12] Koczkur, Kallum M., Stefanos Mourdikoudis., Lakshminarayana Polavarapu., d'eand Sara E. Skrabalak,. "Polyvinylpyrrolidone (PVP) in Nanoparticle Synthesis". Journal of The Royal Society of Chemistry. 2015. 